\title{
Sensitisation to lipid transfer proteins in pollen - allergic adults with food allergy
}

\author{
Adam Wawrzeńczyk ${ }^{1}$, Magdalena Żbikowska-Gotz ${ }^{1}$ Anna Wawrzeńczyk², Zbigniew Bartuzi ${ }^{1}$
}

${ }^{1}$ Department and Clinic of Allergology, Clinical Immunology and Internal Medicine, Collegium Medicum in Bydgoszcz, Nicolaus Copernicus University in Torun, Poland

2Department and Clinic of Vascular Diseases and Internal Medicine, Collegium Medicum in Bydgoszcz, Nicolaus Copernicus University in Torun, Poland

Adv Dermatol Allergol 2020; XXXVII (4): 508-512

DOI: https://doi.org/10.5114/ada.2020.98278

\begin{abstract}
Introduction: Food allergy affects $6-17 \%$ of Europeans and in $60 \%$ of the cases it is accompanied by inhalation allergy. This is due to two phenomena, namely co-sensitisation and cross-reactivity, which are caused by panallergens, such as lipid transfer proteins (LTP). These proteins are classified as defence proteins PR-14 and are responsible for protecting the plant from bacterial and fungal infections. Clinically, LTP allergy manifests with severe anaphylactic reactions or milder reactions, such as oral allergy syndrome.

Aim: To assess the incidence of specific lgE to components belonging to LTP based on molecular testing.

Material and methods: The study was conducted at the Department of Allergy, Clinical Immunology and Internal Diseases in Bydgoszcz, Poland. A total of 50 subjects participated in the study. Each subject had their aslgE levels determined with ImmunoCap ISAC.

Results and Conclusions: Antigen-specific IgE antibodies to LTP components were identified in $24 \%$ of the subjects. In subjects with LTP allergy, adverse skin reactions were the most common after consumption of sensitising foods. Peach was the most common food allergen triggering these reactions. The Artemisia vulgaris component Art $v 3$ was the precursor of LTP allergy in our study population: the highest incidence and the highest mean levels of aslgE were demonstrated for this component.
\end{abstract}

Key words: food allergy, allergenic components, cross-reactivity, lipid transfer protein.

\section{Introduction}

The European Academy of Allergy and Clinical Immunology (EAACI) reported in 2014 that $6-17 \%$ of Europeans were affected by food allergy [1]. In $60 \%$ of the food-allergic adults and children, food allergy co-exists with inhalation allergy [2]. This is due to two phenomena, namely co-sensitisation and cross-reactivity. Co-sensitisation is defined as the presence of allergen-specific lgE (aslgE) for both inhalant and food allergens in a patient. Cross-reactivity, on the other hand, refers to a situation where an IgE antibody originally produced in response to one allergen binds with a similar allergen but of a different origin [3]. Cross-reactions most commonly occur between pollen allergens and foods of plant origin belonging to the same family of proteins and are caused by ubiquitous and structurally similar panallergens [4]. Panallergens contain highly conserved regions of amino acid sequences and share a similar three-dimensional structure, thus meeting the requirement for mutual cross-recognition by lgE [3-6].

Lipid transfer proteins (LTP) belong to the prolamin superfamily of proteins, are ubiquitous in the plant kingdom, predominate among the fruits of the Rosaceae family, and are classified as panallergens. LTPs are associated with the defence system of plants and are responsible for protecting the plant from bacterial and fungal infections, and belong to the PR-14 family of defence proteins. Plant LTPs are subdivided into specific and non-specific (nsLTP), and the latter have been demonstrated to cause allergy (Table 1) [7]. LTPS are also subdivided based on molecular mass into three types: LTP1 (9 kDa), LTP2 (7 kDa) and LTP3 (11 kDa). These proteins are resistant to external factors, such as high temperature or pepsin. LTPs are involved in transporting monomers required for the formation of cuticle on the

Address for correspondence: Adam Wawrzeńczyk, Department and Clinic of Allergology, Clinical Immunology and Internal Medicine, Jan Biziel University Hospital No. 2, 75 Ujejskiego St, 85-168 Bydgoszcz, Poland, phone: +48 602531 231, e-mail: adanw23@gmail.com Received: 12.12 .2018 , accepted: 28.12 .2018 . 
Table 1. Selected lipid transfer proteins recognised as allergens [7]

\begin{tabular}{|c|c|}
\hline Origin & Allergens \\
\hline \multicolumn{2}{|l|}{ Tree pollen: } \\
\hline Hazelnut (Corylus avellana) & Cor a 8 \\
\hline Sweet Chestnut (Castanea sativa) & Cas s 8 \\
\hline Olive (Olea europaea) & Ole e 7 \\
\hline London plane (Platanus acerifolia) & Pla a 3 \\
\hline \multicolumn{2}{|l|}{ Weed pollen: } \\
\hline Common ragweed (Ambrosia artemisiifolia) & Amb a 6 \\
\hline Common mugwort (Artemisia vulgaris) & Art v 3 \\
\hline Spreading pellitory (Parietaria judaica) & Par j 1, Par j 2 \\
\hline \multicolumn{2}{|l|}{ Fruits: } \\
\hline Peach (Prunus persica) & Pru p 3 \\
\hline Apricot (Prunus armeniaca) & Pru ar 3 \\
\hline Apple (Malus domestica) & Mal d 3 \\
\hline Cherry (Prunus avium) & Pru av 3 \\
\hline Pear (Pyrus communis) & Pyr c 3 \\
\hline Plum (Prunus domestica) & Pru d 1 \\
\hline Raspberry (Rubus idaeus) & Rub i 3 \\
\hline Strawberry (Fragaria ananasa) & Fra a 3 \\
\hline Blackberry (Morus nigra) & Mor n 3 \\
\hline Orange (Citrus sinensis) & Cit s 3 \\
\hline Mandarin (Citrus resticulata) & Cit $\mathrm{r} 3$ \\
\hline Lemon (Citrus limon) & Cit I 3 \\
\hline Grape (Vitis vinifera) & Vit v 1 \\
\hline Banana (Musa acuminate) & Mus a 3 \\
\hline Kiwi (Actinidia chinensis) & Act d 10 \\
\hline
\end{tabular}

\begin{tabular}{lc}
\hline Origin & Allergens \\
\hline Vegetables: & \\
\hline Tomato (Solanum lycopersicum) & Sola I 3, Sola I 6 \\
\hline Onion (Allium cepa) & All c 3 \\
\hline Cabbage (Brassica oleracea) & Bra o 3 \\
\hline Lettuce (Lactuca sativa) & Lac s 1 \\
\hline Celery (Apium graveolens) & Api g 2, \\
\hline Parsley (Petroselinum crispum) & Api g 6 \\
\hline Asparagus (Asparagus officinalis) & Pet c 3 \\
\hline Cereals: & Asp o1 \\
\hline Wheat (Triticum aestivum) & \\
\hline Rice (Oryza sativa) & Tri a 14 \\
\hline Barley (Hordeum vulgare) & Ory s 14 \\
\hline Maize (Zea mays) & Hor v 14 \\
\hline Nuts: & Zea m14 \\
\hline Peanut (Arachis hypogaea) & \\
\hline Hazelnut (Corylus avellana) & Hel a 3 \\
\hline Walnut (Juglans regia) & Sin a 3 \\
\hline Almond (Prunus dulcis) & Hev b 12 \\
\hline Seeds: & Cor a 8 \\
\hline Sunflower (Helianthus annuus) & Jug 3 \\
\hline White mustard (Sinapis alba) & \\
\hline Latex: & \\
\hline
\end{tabular}

surface of plant organs, which is why they mainly accumulate in the external tissues of plants, the skin and the peel. Concentrations of LTP in a single plant vary, depending on the plant maturity, storage conditions and species [6].

\section{Aim}

The aim of our study was to assess the incidence of specific lgE to components belonging to LTP based on molecular testing (ImmunoCAP ISAC) in adults with pollen allergy.

\section{Material and methods}

A total of 50 adults were included in the study: 30 women and 20 men, aged 18-74 years (mean: 35.8; SD: 12.8; median: 34), with a diagnosis of aerogenic allergy established on the basis of the history and positive skin prick tests, who developed adverse symptoms after consuming foods. The subjects were recruited from among patients of the Department of Allergy, Clinical Immunology and Internal Diseases, Ludwik Rydygier Collegium Medicum in Bydgoszcz, Poland, and the Allergy Outpatient Services of

University Hospital No. 2 in Bydgoszcz, Poland, between 1.06.2014 and 1.06.2017. Severe chronic medical conditions, autoimmune diseases, cancer, allergen-specific immunotherapy, and intake of medications that could interfere with the study results were the main exclusion criteria. Patients below 18 years of age, pregnant women, and breastfeeding women were also excluded from the study,

Each subject had a targeted medical history taken, underwent a physical examination, and had their aslgE levels determined with ImmunoCap ISAC. Each subject had fasting venous blood collected from a cubital vein with a Vacutainer closed system into a tube without an anticoagulant. The blood samples were centrifuged at 3000 revolutions per minute for $15 \mathrm{~min}$ at room temperature using a Sigma $2 \mathrm{~K} 15$ centrifuge, and the resulting serum was aliquoted into Eppendorf tubes and stored at $-20^{\circ} \mathrm{C}$ for further analysis. ISAC is a test for semi-quantitative determination of IgE in serum samples. The solid phase in this test is provided by the surface of a plate on which 112 components (43 native and 69 recombinant) have been adsorbed and arranged in triplets. The ImmunoCAP ISAC test was performed according to the manufacturer's instructions. Prior to the testing, 
the stored serum of a subject was thawed. Using a pipette, $20 \mu \mathrm{l}$ of a subject's serum was applied on one of the four testing fields available on the chip and incubated at room temperature for 120 min in the wet chamber provided by the manufacturer. After incubation, the chip with serum was washed with a washing solution for $10 \mathrm{~min}$, then washed with demineralised water for $5 \mathrm{~min}$, and dried. In the subsequent step of the analysis, $20 \mu \mathrm{l}$ of a solution containing the so-called fluorescence labelled secondary antibodies to human IgE were applied with a pipette on the testing field of the chip. The plates were then incubated at room temperature for $60 \mathrm{~min}$ in the wet chamber. The final step of preparing the chip for reading involved washing it with Solution A for 10 min and with demineralised water for 5 min, followed by complete drying. The surface-bound allergen components react with specific antibodies present in the serum sample. The specific lgE antibodies bound to the support surface are demonstrated by adding fluorescent labelled antihuman IgE antibodies. Fluorescence was quantified using a LuxScan 10K/A scanner from CapitalBiO. The scanner was calibrated according to ISAC test manufacturer's procedures. Scanner parameters were defined in the testing plate measurement procedure. The level of specific IgE antibodies is proportional to the measured intensity of fluorescence. The result was processed on a computer using Microarray Image Analysis (MIA) software. Antibody levels were expressed in standardised units, ISU-E (ISAC Standardised Unit for specific IgE). The measured values ranged from 0.3 to 100 ISU-E, and values $\geq 0.30$ ISU-E were considered to be positive results.

Participation in the study was voluntary. The research topic and the methodology were approved by the Bioethics Committee at the Nicolaus Copernicus University in Torun, Collegium Medicum in Bydgoszcz (approval No. KB 323/2014).

\section{Statistical analysis}

Statistical analysis was performed using the following software: Statistica (StatSoft, USA), SPSS (IBM, USA) and Excel (Microsoft, USA).

\section{Results}

ImmunoCAP ISAC detects specific antibodies to the following LTP components: Pru p 3, Cor a 8, Jug r 3, Ara h 9, Tri a 14, Pla a 3, Ole e 7, Par j 2, and Art v 3. Specific antibodies to LTP were detected in 12 (24\%) subjects (range: 0.3-34 ISU-E; mean: 5.26 ISU-E). The frequency, mean, standard deviation, median, minimum value, and maximum value were calculated for the detected levels of specific IgE belonging to LTP. The data are presented in Table 2.

On average, subject with detectable aslgE to LTP had aslgE for 3.5 LTP components belonging. However, in the largest number of subjects, 5 (41\%), antibodies to just one LTP component were detected (4 subjects with isolated allergy to Art v 3, 1 subject with isolated allergy to Pru p 3). Seven subjects had allergy to LTP components that were inhalant and food allergens, 4 subjects to inhalant LTP only, and 1 subject to food LTP only. The data are given in Figure 1.

In 11 out of 12 subjects allergic to LTP, ISAC demonstrated simultaneous presence of aslgE to components of other panallergens. Antigen-specific IgE to PR10 proteins (Bet $v 1$ homologues) were detected in 9 (75\%) subjects, aslgE to storage proteins (SP) in seeds were detected in $3(25 \%)$ subjects, aslgE to profilin in $2(16.6 \%)$ subjects, aslgE to tropomyosin in 1 (8.3\%) subject, and aslgE to serum albumin in 1 (8.3\%) subject.

The ISAC test results were analysed statistically and clinically with details from the subjects' histories. The largest number of subjects with detected aslgE to LTP components, namely 10 subjects, reported adverse skin reactions (urticaria, angioedema, atopic dermatitis). Anaphylaxis occurred in $25 \%$ of subjects allergic to LTP. More than one adverse symptom (mean: 2.92) following ingestion of a sensitising food were reported by 11 out of $12(91.1 \%)$ subjects. None of the subjects presented with isolated symptoms of oral allergy syndrome (OAS). Only one of the subjects with LTP allergy reported an isolated episode of anaphylaxis. Detailed data are provided in Figure 2.

Table 2. Descriptive statistics for levels of specific IgE belonging to LTPS

\begin{tabular}{|c|c|c|c|c|c|c|}
\hline LTP components & $N$ & Mean & Standard deviation & Median & Minimum & Maximum \\
\hline Art $\vee 3$ & 9 & 8.4 & 10.8 & 4.0 & 0.3 & 34.0 \\
\hline Pru p 3 & 6 & 6.0 & 8.2 & 1.1 & 0.4 & 23.0 \\
\hline Jug r 3 & 6 & 4.8 & 7.1 & 1.8 & 0.7 & 19.0 \\
\hline Pla a 3 & 6 & 3.6 & 5.7 & 1.2 & 0.4 & 15.0 \\
\hline Ara h 9 & 5 & 6.2 & 8.7 & 1.6 & 0.6 & 21.0 \\
\hline Cor a 8 & 4 & 5.3 & 7.8 & 1.8 & 0.6 & 17.0 \\
\hline Ole e 7 & 3 & 0.9 & 0.4 & 0.8 & 0.6 & 1.4 \\
\hline Tri a 14 & 2 & 3.2 & 0.1 & 3.2 & 3.1 & 3.2 \\
\hline Par j 2 & 1 & 1.5 & & 1.5 & 1.5 & 1.5 \\
\hline
\end{tabular}




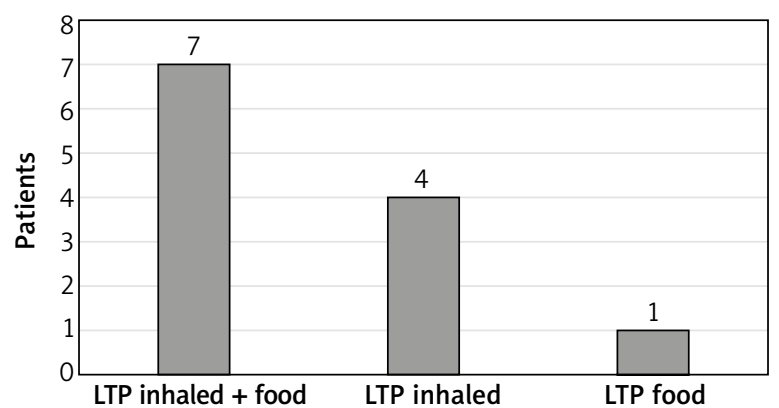

Figure 1. Source of sensitising LTP

Analysis of the ISAC test results in the context of the subjects' histories revealed that adverse reactions most commonly occurred after consumption of peaches (7 subjects). Detailed data on sensitising foods are provided in Figure 3.

\section{Discussion}

LTPs are the most common cause of food-induced allergy in adults inhabiting the Mediterranean region [8]. This is attributed to the fact that the local diets are rich in fruits of the Rosaceae family (peach, apricot, quince, almond). The first LTP fully identified and characterised as an allergen was a major allergen of peach, Pru $p 3$. Peach is the most common cause of LTP-associated allergy, and Pru p 3 is also considered to be a precursor of allergy to other nsLTPs [9-11].

The incidence of LTP-associated food allergy varies. A study by Nucera et al. from Italy [12] demonstrated that the incidence of LTP allergy in subjects with food allergy was as high as $84.1 \%$. A different incidence of LTP allergy was reported by Faber et al. [13] from Belgium, who demonstrated antibodies to LTP in $24.6 \%$ of the subjects. These results are consistent with those of our study, in which aslgE to LTP were detected in the serum of 24 subjects. The differences in the incidence of LTP allergy are most likely due to the geographical region. The incidence of LTP allergy is higher in Italy than in Poland or Belgium and this difference is due to the differences in diets (different amount of fruit of the Rosaceae family consumed in both regions).

Clinically, LTP allergy manifests with severe anaphylactic reactions or milder reactions, such as oral allergy syndrome (OAS) [9]. In subjects with detected aslgE to LTP components, the largest number of patients reported cutaneous symptoms (83\%), followed by OAS (75\%), shortness of breath (41.5\%), and gastrointestinal symptoms (16.6\%). Anaphylactic reaction occurred in $25 \%$ of subjects allergic to LTP. Our results are for the most part consistent with findings reported by Pascal et al. [14]. In their study, allergy to LTP manifested with: OAS in $75.6 \%$ of the subjects, urticaria in $66.7 \%$, gastrointestinal symptoms in $55.6 \%$, and anaphylaxis in $75.6 \%$. The higher rate of anaphylaxis in the study by

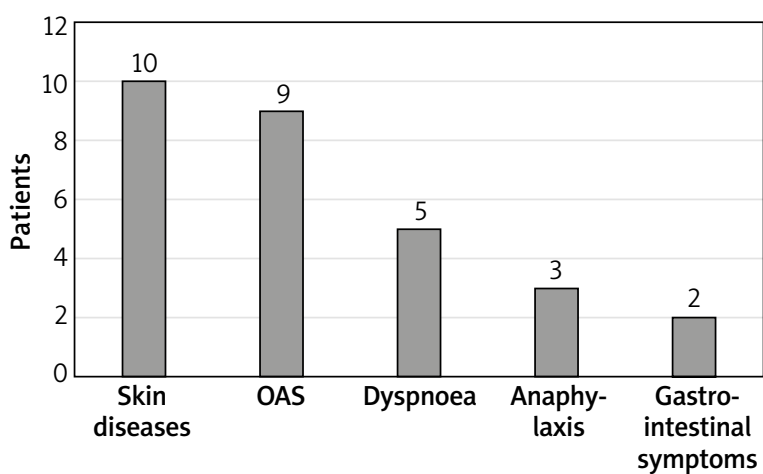

Figure 2. Adverse reactions in subjects with LTP allergy

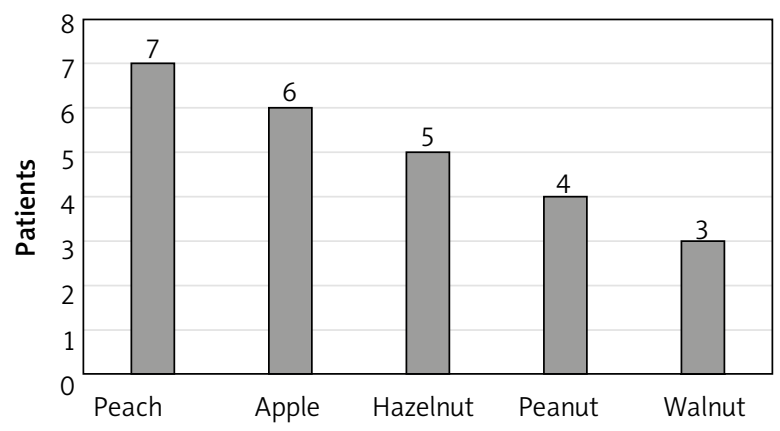

Figure 3. Number of subjects with LTP allergy who reported adverse reactions to specific foods

Pascal et al. may be due to the differences in eating habits within the study population. The study was conducted in Barcelona, Spain, where consumption of fruits of the Rosaceae family is much higher than that in Poland.

Peach is the most common cause of LTP-associated allergy. In our study, subjects allergic to LTP most commonly reported adverse reactions after consuming a peach, an apple or nuts. In a study by Aseero [15], five foods that most commonly caused symptoms in patients with LTP were identical to those in our study. In Aseero study, the most common sensitising foods were peach (100\%), walnut (60\%), apple (54\%), hazelnut (46.6\%), and peanuts (40\%).

The major peach allergen Pru $\mathrm{p} 3$ is also considered to be a precursor of allergy to other LTP. In our study, aslgE for Pru $p 3$ was demonstrated in the serum of 6 subjects. The most common sensitising LTP was Art v 3 (an Artemisia vulgaris protein), with aslgE demonstrated in 9 subjects. Furthermore, aslgE to Jug $r 3$ and Pla a 3 were detected in 6 subjects, to Ara $h 9$ in 5 subjects, to Cor a 8 in 4 subjects, to Ole e 7 in 3 subjects, to Tri a 14 in 2 subjects, and to Par $j 2$ in 1 subject. The highest mean levels of aslgE were identified for: Art v 3 (8.36), Ara h 9 (6.16), Pru p 3 (5.45), Cor a 8 (5.28), Jug r 3 (4.8), Pla a 3 (3.62), Tri a 14 (3.15), Par j 2 (1.5), and Ole e 7 (0.93). Our results differ from those of Pascal et al. [14]. In the latter study, the incidence rates of allergy to LTP components were as follows: $100 \%$ for Pru p 3, 68.9\% for Pla a 2, 64.4\% for Art v 3, 57.8\% for Cor a 8, and $28.6 \%$ 
for Par j 2. The highest median ISU-E was observed for: Pru p 3 (3), Pla a 2 (0.8), Art v 3 (0.6), Cor a 8 (0.5), and Par j 2 (0.3). Similar results for LTP allergy to those in our study were reported by Gao et al. [16]. The study was conducted in China, where peaches are not a very common food but the concentration of Artemisia vulgaris pollen is high. In this study, aslgE antibodies to Art $\vee 3$ were detected in $60 \%$ of the subjects, and those to Pru $\mathrm{p} 3$ in 51\%. The mean levels of antibodies to Art $\vee 3$ were significantly higher than those for Pru $p 3$.

Given the higher incidence of allergy to Art v3 compared to allergy to Pru p 3, and due to the higher mean level of ISU-E for Art v 3 compared to Pru p 3, a detailed analysis of subjects allergic to LTP was carried out. Only in 1 out of 12 subjects, no aslgE to either Art $v 3$ or Pru p 3 was detected. In 2 subjects, aslgE to Art $\vee 3$ and Pru p 3 was identified, but these findings were excluded from further analysis because the detected concentrations were at the limit of detection for ImmunoCAP ISAC. The remaining subjects could be divided into two groups. The first group consisted of subjects with aslgE to Art v 3 but not to Pru p 3 (5 subjects) and subjects in whom the levels of aslgE to Art $\vee 3$ were higher than those of aslgE to Pru p 3 (1 subject), giving a total of 6 out of 9 subjects (66\%). The second group consisted of subjects with aslgE to Pru $\mathrm{p} 3$ but not to Art v 3 (1 subject) and subjects in whom the levels of aslgE to Pru p 3 were higher than those of aslgE to Art v 3 (2 subjects), giving a total of 3 out of 9 subjects (33\%). Interestingly, all the subjects with allergy predominantly to Pru p 3 and none of the subjects with allergy predominantly to Art $\vee 3$ developed anaphylaxis. Also Gao et al. [16] divided their study population into two groups, one in which allergy to Art $\vee 3$ predominated (majority of the subjects) and the other in which allergy to Pru p 3 was more prevalent.

The results of our study and the cited papers suggest a possibility of two pathways of sensitisation to LTP. The first pathway is observed in the countries of the Mediterranean region, where Pru $\mathrm{p} 3$, a protein of the peach, an important dietary ingredient in this region, is the cause and precursor of LTP allergy. On the other hand, in countries where peaches are not an important ingredient of the diet, but concentrations of Artemisia vulgaris pollen are high, Art v 3 , a component of Artemisia vulgaris pollen, is the cause and precursor of LTP allergy. Also Garcia-Sellies et al. [17] and Lombardero et al. [18] address the two possible mechanisms of allergy to LTP in their papers.

\section{Conclusions}

Specific IgE antibodies to LTP components were identified in $24 \%$ of the subjects in our study population. In subjects with LTP allergy, adverse skin reactions were the most common after consumption of sensitising foods. Peach was the most common food allergen triggering these reactions. The Artemisia vulgaris component Art $\vee 3$ was the precursor of LTP allergy in our study popu- lation: the highest incidence and the highest mean levels of aslgE were demonstrated for this component.

\section{Conflict of interest}

The authors declare no conflict of interest.

\section{References}

1. Muraro A, Werfel T, Hoffmann-Sommergruber K, et al., EAACl food allergy and anaphylaxis guidelines: diagnosis and management of food allergy. Allergy 2014; 69: 1008-25.

2. Werfel T, Asero R, Ballmer-Weber BK, et al. Position paper of the EAACl: food allergy due to immunological cross-reactions with common inhalant allergens. Allergy 2015; 70: 1079-90.

3. Bartuzi Z, Kaczmarski M, Czerwionka-Szaflarska M, et al. Position paper if Food Allergy Section the Polish Society of Allergology on the diagnosis and mamagment of food allergies. Pol J Allergol 2017; 4: 109-22.

4. Hauser M, Roulias A, Ferreira F, Egger M. Panallergens and their impact on the allergic patient. Allergy Asthma Clin Immunol 2010; 6: 1 .

5. Chwała C. Białka transportujące lipidy. Alergia 2012; 3: 31-3.

6. Salcedo G, Sanchez-Monge R, Diaz-Perales A, et al. Plant nonspecific lipid transfer proteins as food and pollen allergens. Clin Exp Allergy 2004; 34: 1336-41.

7. Pałgan K, Bartuzi Z. Czynniki genetyczne i środowiskowe w rozwoju alergii pokarmowej. Postepy Hig Med Dosw 2012; 66: 385-91.

8. Matricardi PM, Kleine-Tebbe J, Hoffmann HJ, et al. EAACI molecular allergology user's guide. Pediatr Allergy Immunol 2016; 27 Suppl 23: 1-250.

9. Ortolani C, Ispano M, Pastorello E, et al. The oral allergy syndrome. Ann Allergy 1988; 61: 47-52.

10. Bartuzi Z. Nowe spojrzenie na alergeny pokarmowe. Alergia 2011; 2: 31-7.

11. Pastorello EA, Farioli L, Pravettoni V, et al. The major allergen of peach (Prunus persica) is a lipid transfer protein. J Allergy Clin Immunol 1999; 103: 520-6.

12. Nucera E, Mezzacapp S, Aruanno A, et al. Hypersensitivity to major panallergens in a population of 120 patients. Adv Dermatol Allergol 2015; 32: 255-61.

13. Faber M, Van Gasse A, Decuyper I, et al. IgE-reactivity profiles to nonspecific lipid transfer proteins in a northwestern European country. J Allergy Clin Immunol 2017; 139: 679-82.

14. Pascal M, Munoz-Cano R, Reina Z, et al. Lipid transfer protein syndrome: clinical pattern, cofactor effect and profile of molecular sensitization to plant-foods and pollens. Clin Exp Allergy 2012; 42: 1529-39.

15. Aseero R. In patients with LTP syndrome food-specific IgE show a predictable hierarchical order. Eur Ann Allergy Clin Immunol 2014; 46: 142-6.

16. Gao ZS, Yang ZW, Wu SD, et al. Peach allergy in China: a dominant role for mugwort pollen lipid transfer protein as a primary sensitizer. J Allergy Clin Immunol 2013; 131: 224-6.

17. Garcia-Sellies FJ, Dıaz-Perales A, Sanchez-Monge R, et al. Patterns of reactivity to lipid transfer proteins of plant foods and Artemisia pollen: an in vivo study. Int Arch Allergy Immunol 2002; 128: 115-22.

18. Lombardero M, Garcia-Selles FJ, Polo F, et al. Prevalence of sensitization to Artemisia allergens Art v 1, Art v 3 and Art v 60 kDa. Cross-reactivity among Art $v 3$ and other relevant lipid-transfer protein allergens. Clin Exp Allergy 2004; 34: 1415-21. 